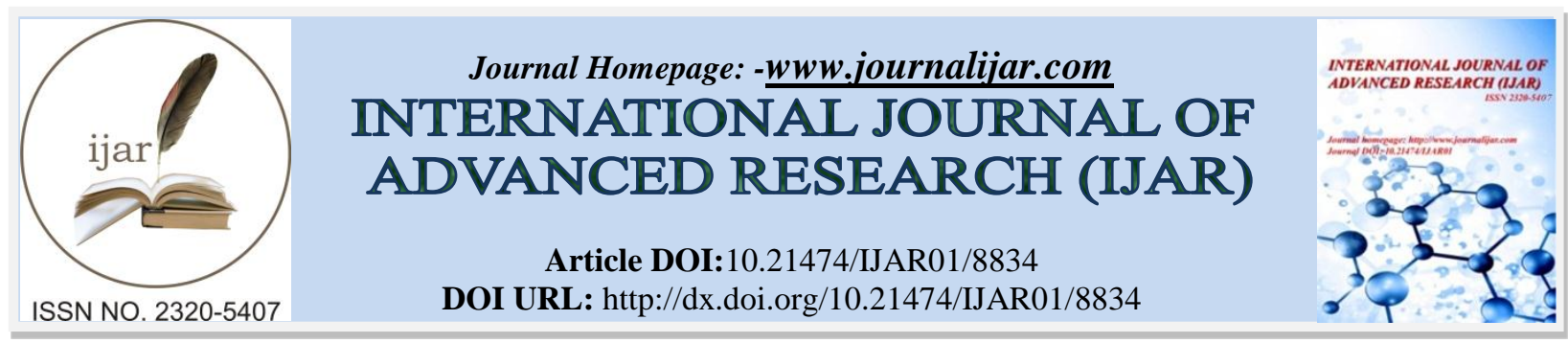

RESEARCH ARTICLE

\title{
PHYSICO-MECHANICAL PROPERTIES OF TYPHA ANGUSTATA FIBER REINFORCED POLYSTYRENE BIO-COMPOSITES.
}

Walid Bin Kader ${ }^{1}$, Tanvir sultana ${ }^{2}$ and Md. Wahab Khan ${ }^{1}$.

Department of Chemistry, Bangladesh University of Engineering and Technology (BUET), Dhaka.

\section{Manuscript Info}

Manuscript History

Received: 06 February 2019

Final Accepted: 08 March 2019

Published: April 2019

Key words:-

Typha angustata fiber,Composite, Tensile strength,Water absorption, Polystyrene

\begin{abstract}
Natural fibers are considered to have potential use as reinforcing material in polymer matrix composites because of their good strength, stiffness, low cost, environmental friendly and biodegradability. Elephant grass (Typha Angustata) fiber is used as new natural fiber reinforcement and polystyrene as matrix. Typha Angustata fibers (TAF) were extracted and used to prepare sodium hydroxide treated and untreated TAF reinforced polystyrene composites. Composites were prepared with randomly oriented fibers with different proportions of fibers and matrix ratio. Different types of compression molded TAF-polystyrene composite were prepared using different weight percent of treated and untreated TAF with compositions 5 , $15,20,25$ and 30 wt. $\%$ in polystyrene. Mechanical tests i.e. impact and hardness tests were performed. The results showed that, as the fiber volume fraction and composite post curing time increases the mechanical properties of the composite increases.
\end{abstract}

Copy Right, IJAR, 2019,. All rights reserved.

\section{Introduction:-}

Many researchers, scientists and engineers have done rigorous research to develop the biodegradable and sustainable composites using natural fiber ${ }^{(1)}$. Synthetic fiber shows impressive mechanical, thermal properties and durability but when we think about its disposal processing it produces huge amount of black smoke and bad smell. To overcome the problem, the importance of natural fiber based composites is demanding to make the world green. Natural fibers have made a remarkable impact as a potential substitute for conventional synthetic fibers like aramid and glass fiber over a past few decades. Because of their mechanical properties, good thermal insulation properties, low density, nonabrasive nature, easy availability from restorable sources, cheaper prices and recyclability of natural fiber reinforced polymer composites have attracted the composite industry, both for structural and nonstructural applications ${ }^{(2)}$. In this research work, typha angustata fiber was used as reinforcing materials with thermoplastics to make composites. Typha Angustata is a perennial plant and is an aquatic weed and is widely grown in waterlogged areas and it belongs to the family Typhaceae in the plant kingdom ${ }^{(3)}$. It is highly available in Bangladesh as waste fiber.

Composites are used in various applications such as households, packaging, aerospace, sports and automobile industries by replacing metallic components due to their inherent light weight and immune to corrosion ${ }^{(4,5)}$. However, natural fiber gives rise to incompatibility between fiber and polymer in composites due to hydrophilic nature. Natural fibers are composed of cellulose, hemicellulose, lignin, pectin, wax and ash. Chemical treatment of natural fibers can solve the limitations due to hydrophilic nature by purifying the fiber surface, chemically modify

Corresponding Author:- Md. Wahab Khan.

Address:-Department of Chemistry, Bangladesh University of Engineering and Technology

(BUET), Dhaka. 
the surface, prevent the moisture absorption and gives the better compatibility between fiber and polymer in composites ${ }^{(6)}$. Siregar et al. investigated and reported on effect of alkali $(\mathrm{NaOH})$ treatment on the mechanical properties of pineapple leaf fiber (PALF) reinforced high impact polystyrene (HIPS) composites ${ }^{(7)}$. They obtained highest mechanical properties value for the short PALF treatment with $\mathrm{NaOH}$ concentration of $4 \%$. Ponnukrishnan et al. investigated on effect of the alkali $(\mathrm{NaOH})$ treatment on tensile properties of typha domingensis reinforced polyester and reported increase in the strength of composite with the increase of fiber content in the polyester matrix $^{(8)}$. Tanvir sultana et al. worked on effect on the properties of low density polyethylene composites reinforced with treated and untreated betel nut husk fibers. They reported that alkali $(\mathrm{NaOH})$ treated based composites notably gave better compatibilities than untreated fiber based composites ${ }^{(9)}$. In the recent years, it has been noticed that not much appreciable researches have been carried out on the optimized surface treatment, manufacturing techniques and product application using the typha angustata fibers. So there are more scope to develop economically and ecologically superior engineering material by utilizing these typha angustata fibers and its composites ${ }^{(9)}$.

In this research work, typha angustata fiber was treated with sodium hydroxide to improve its adhesion with polystyrene. The vision of this research work is to find out the effects of treated and untreated typha angustata fiber loading on the physico-mechanical properties typha angustata fiber- polystyrene composites.

\section{Experimental Part:-}

Surface modification of typha angustata fibers by sodium hydroxide:-

Typha angustata fibers were immersed in aqueous solution of sodium hydroxide (6\%) (w/w) for one hour at room temperature approximately $25^{\circ} \mathrm{C}$ and the fibers were stirred occasionally. Fiber to liquor ratio was $1: 20$ (w/v). The alkali treated typha angustata fiber were thoroughly washed in tap water and then immersed in distilled water for 24 hrs. Finally, fibers were washed with distilled water to remove the alkali completely and the $\mathrm{pH}$ was measured until it was found neutral. The alkali treated typha agustata fiber were dried in air first then further dried in an oven to get a constant weight.

\section{Fabrication of composites by compression molding technique:-}

Treated and untreated typha angustata fibers were dried in an oven at $80^{\circ} \mathrm{C}$ for 24 hours before fabrication of composites. Polystyrene was granulated in a grinder and dried at $80^{\circ} \mathrm{C}$ for 3 hours. The polystyrene and TAF were dry-blended in a blender for one minute. These mixtures were molded in a compression molding machine (Paul-Otto Weber Press Machine) at a molding temperature of $180^{\circ} \mathrm{C}$. The composites were fabricated in the ratio of composition $5 \%$ TAF - 95\% polystyrene, $10 \%$ TAF - 90\% polystyrene, $15 \%$ TAF - $85 \%$ polystyrene, $20 \%$ TAF $80 \%$ polystyrene, $25 \%$ TAF $-75 \%$ polystyrene and $30 \%$ TAF $-70 \%$ polystyrene. The mixtures were hot pressed for 10 minutes and the applied pressure was $200 \mathrm{kN}$. The additional pressure of $50 \mathrm{kN}$ was applied to get voids free compression molded composite. The composite was allowed to cool and then completely cured composite was taken out from the mold. The same conditions of time, temperature, heating time, pressure and cooling time were maintained to prepare all composites. Finally, the compression molded composites were cut to make specimens of suitable dimension to measure tensile and water absorption properties.

\section{Water absorption test of composites:-}

Sodium hydroxide treated and untreated typha angustata fiber-polystyrene composites were used to conduct water absorption tests. The dimension of each test specimens were $39 \mathrm{~mm}$ x $10 \mathrm{~mm}$ x $4 \mathrm{~mm}$ and the testing was carried out. Three specimens were taken to calculate average results.

\section{Tensile properties of the composites:-}

Using a universal tensile testing machine, model: 1410 Titans, capacity: $5 \mathrm{kN}$, England all the treated and untreated typha angustata fiber-polystyrene composites were used to measure the tensile properties of the composites. Tensile tests were conducted following ASTM D 3039 standard method and the cross head speed of the test was 10 $\mathrm{mm} / \mathrm{min}$.

\section{Results and Discussion:-}

\section{Chemical treatment of typha angustata fibers:-}

In this study, surface modification of typha angustata fiber was done with suitable chemical treatments in order to optimize the effective interfacial bonding between the typha angustata fibers and polystyrene matrix so that the typha angustata fiber reinforced polystyrene composites with improved properties could be prepared. 
Alkali treatment

Fiber $-\mathrm{OH}+\mathrm{NaOH} \quad \longrightarrow$ Fiber $-\mathrm{O}^{-} \mathrm{Na}^{+}+\mathrm{H}_{2} \mathrm{O}$

Reaction between typha angustata fibers and sodium hydroxide:-

Fiber-cell-O-Na groups were formed between the cellulose molecular chains due to the alkali treatment of typha angustata fibers. The effect of alkali on cellulose fiber is a swelling reaction and there is removal of hydrogen bonding present in the network structure and new reactive hydrogen bonds are formed between the cellular molecular chains. As a result hydrophilic hydroxyl groups are reduced and the fibers moisture resistance property is increased and effective fiber surface area for good adhesion with the matrix is increased ${ }^{(10-16)}$.

Possible hypothetical models of interface of typha angustata-polystyrene composites:-

Chemically treated typha angustata fiber surface became more hydrophobic and there is an improvement in surface characteristics such as wetting, adhesion and porosity of typha angustata fibers. Also, there is an improvement in interfacial adhesion between the treated Typha angustata fiber surface and the polystyrene matrix ${ }^{(17-19)}$. The possible hypothetical models of interface of untreated, alkali treated typha angustata fiber -polystyrene composites may be represented as follows based on the hypothetical models proposed by Joseph P. V ${ }^{(20)}$ and Manikandan Nair K. C. $(21)$

Interface of untreated typha angustata fiber - polystyrene composite and treated typha angustata fiberpolystyrene composite:-

A possible hypothetical model of interface of untreated typha angustata fiber surface having hydroxyl groups with the polystyrene matrix and treated typha angustata fiber surface having reactive (- ONa) groups with polystyrene matrix is shown in Figure 1 and Figure 2.

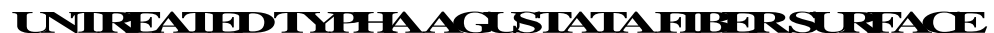

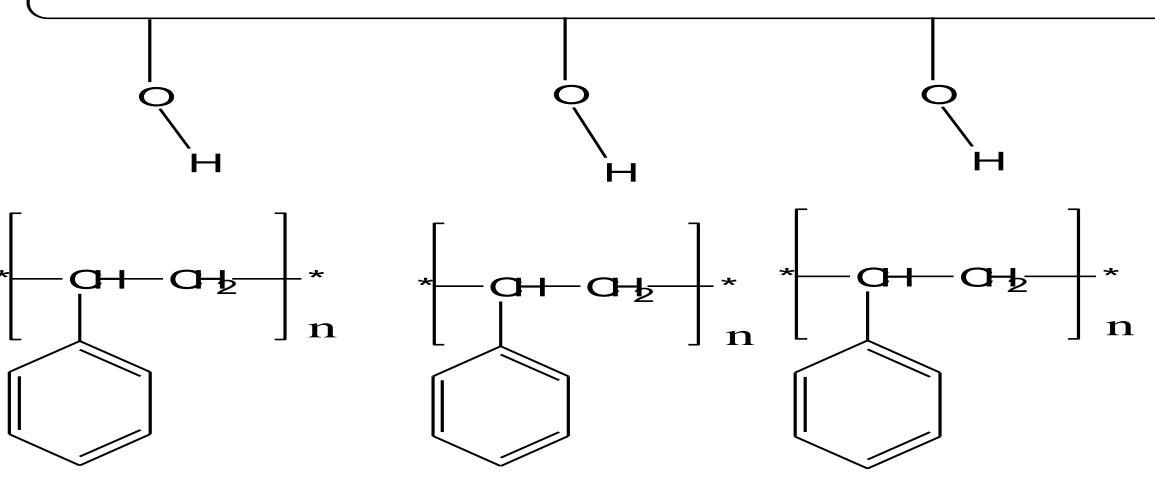

Polystyrene Matrix

Figure 1:-

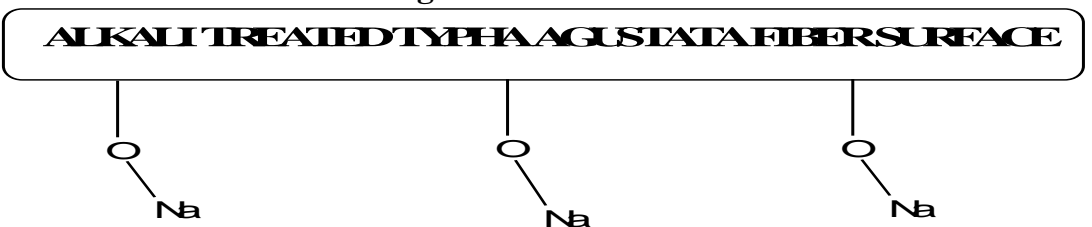<smiles>CC(C)(C)CC(Oc1ccccc1)C(C)(C)C</smiles><smiles>CC(C)(C)COc1ccccc1</smiles><smiles>CC(C)(C)COc1ccccc1</smiles>

PO YSTMRENEMATRTX

Figure 2:-

FTIR spectra of untreated and alkali treated typha angustata fiber:- 
The characteristic bands of untreated and alkali treated TAF are shown in figure 3 and 4 respectively. It is cleared from the figures that the absorption band at $1729.22 \mathrm{~cm}^{-1}$ of untreated TAF has disappeared completely in the treated TAF. This indicates that the alkali treatment of typha angustata fibers had removed the impurities, hemicelluloses and part of lignin. The similar FT-IR data was also reported ${ }^{(9)}$ by Tanvir sultana et al in case of alkali treated typha angustata fibers.

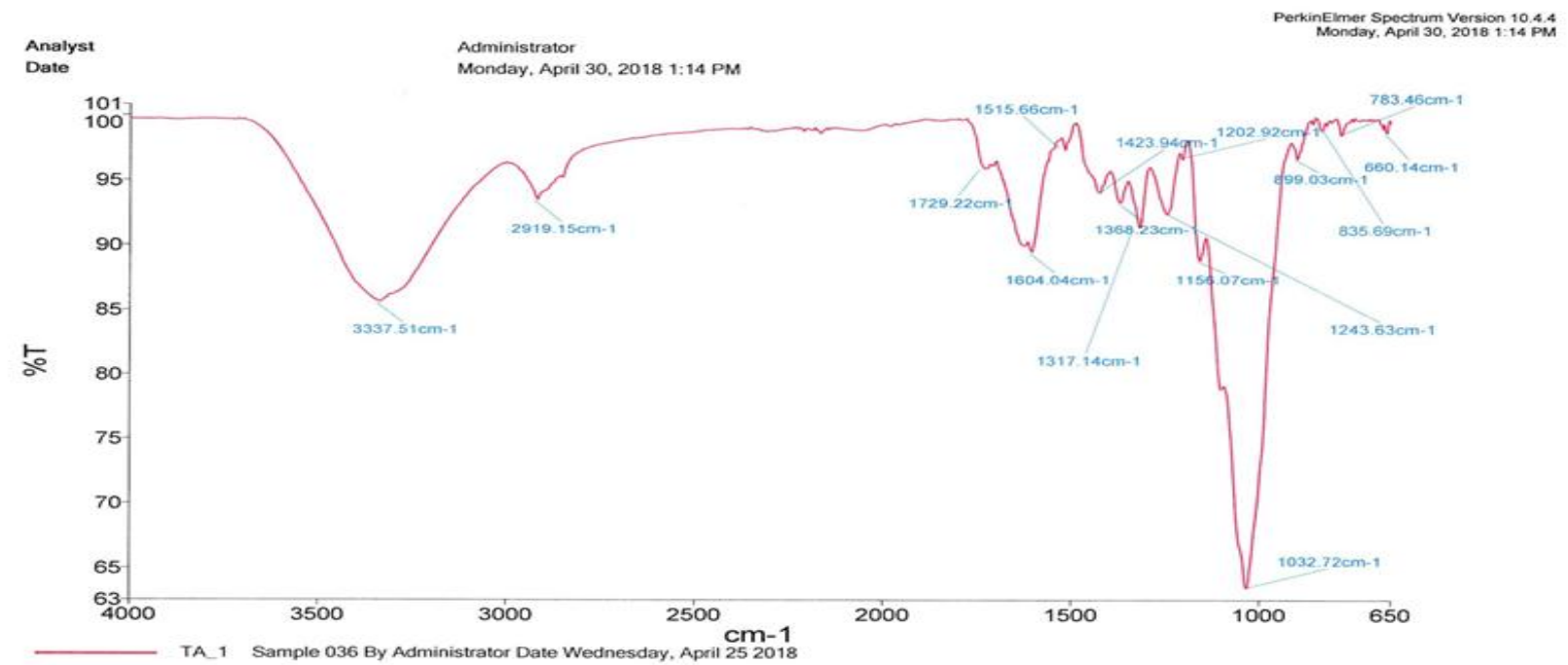

Figure 3:-

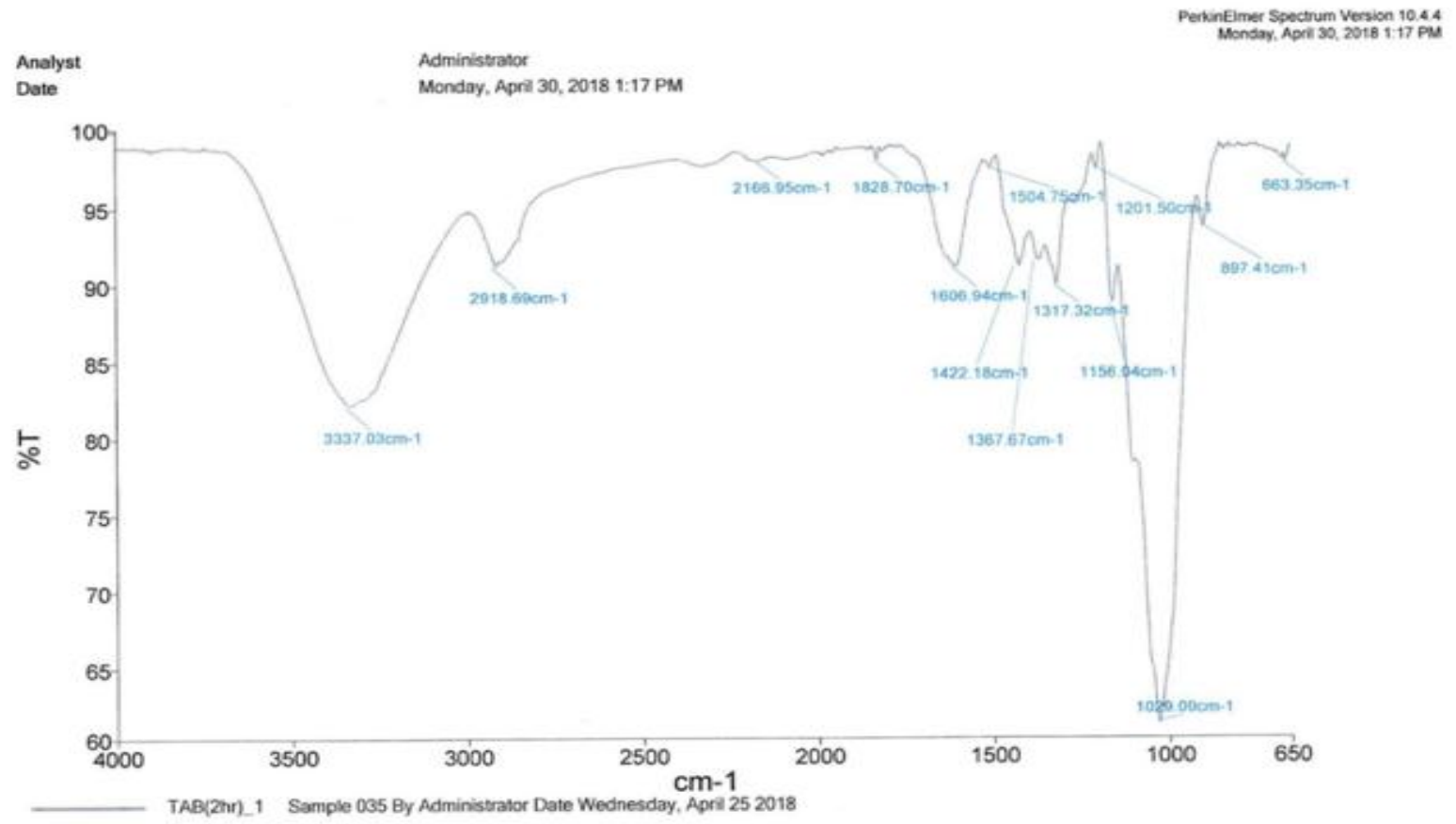

Figure 4:-

\begin{tabular}{|c|c|c|c|}
\hline $\begin{array}{c}\text { Position of bands (cm-1) } \\
\text { untreated TAF }\end{array}$ & Peak assignments & $\begin{array}{c}\text { Position of bands }(\mathrm{cm}-1) \\
\text { treated TAF }\end{array}$ & Peak assignments \\
\hline$\sim 3337.51$ & $\begin{array}{c}\text {-OH stretching from the } \\
\text { cellulose, hemicellulose } \\
\text { and lignin }\end{array}$ & $\sim 3337.03$ & $\begin{array}{c}\text {-OH stretching from the } \\
\text { cellulose, hemi-cellulose } \\
\text { and lignin }\end{array}$ \\
\hline$\sim 2919.15$ & C-H vibration in aromatic & $\sim 2918.69$ & C-H vibration in aromatic \\
\hline
\end{tabular}




\begin{tabular}{|c|c|c|c|}
\hline & ring and alkane & & ring and alkane \\
\hline$\sim 1729.22$ & $\begin{array}{c}\mathrm{C}=\mathrm{O} \text { stretching from the } \\
\text { lignin and hemi-cellulose }\end{array}$ & $\begin{array}{c}\text { and } \\
\text { aromatic in-plane }\end{array}$ & $\begin{array}{c}\mathrm{C}=\mathrm{C} \text { stretching from } \\
\text { aromatic in-plane }\end{array}$ \\
\hline$\sim 1515.66$ & $\begin{array}{c}\mathrm{C}=\mathrm{C} \text { stretching in } \\
\text { aromatic skeletal ring due } \\
\text { to lignin }\end{array}$ & $\begin{array}{c}\mathrm{C}=\mathrm{C} \text { stretching in } \\
\text { aromatic skeletal ring due } \\
\text { to lignin }\end{array}$ \\
\hline$\sim 1423.94$ & $\begin{array}{c}\mathrm{C} \text {-C stretching from } \\
\text { aromatic ring }\end{array}$ & $\sim 1504.75$ & $\begin{array}{c}\text { C-C stretching from } \\
\text { aromatic ring }\end{array}$ \\
\hline
\end{tabular}

Table 1:- FT-IR spectral data of untreated typha angustata fiber and alkali treated typha angustata fiber

Tensile properties of untreated and treated typha angustata fiber and polystyrene composites:-

Tensile strength and elongation at break:-

The tensile strengths of the untreated and treated TAF-Polystyrene composites are shown in figure 5. From the figure it is cleared that the tensile strengths of the composites increased up to $20 \mathrm{wt}$. \% fibers loading and then decreased. The elongations at break of untreated and treated TAF-Polystyrene composites are shown in figure 6. Elongation at break of all composites is decreased with increasing of fiber loading. Tensile properties of all treated TAF-Polystyrene composites are higher than that of untreated TAF-Polystyrene composites. This may be the reason for the better improvement of the fiber-matrix interfacial adhesion in composites which was made by alkali treatment.

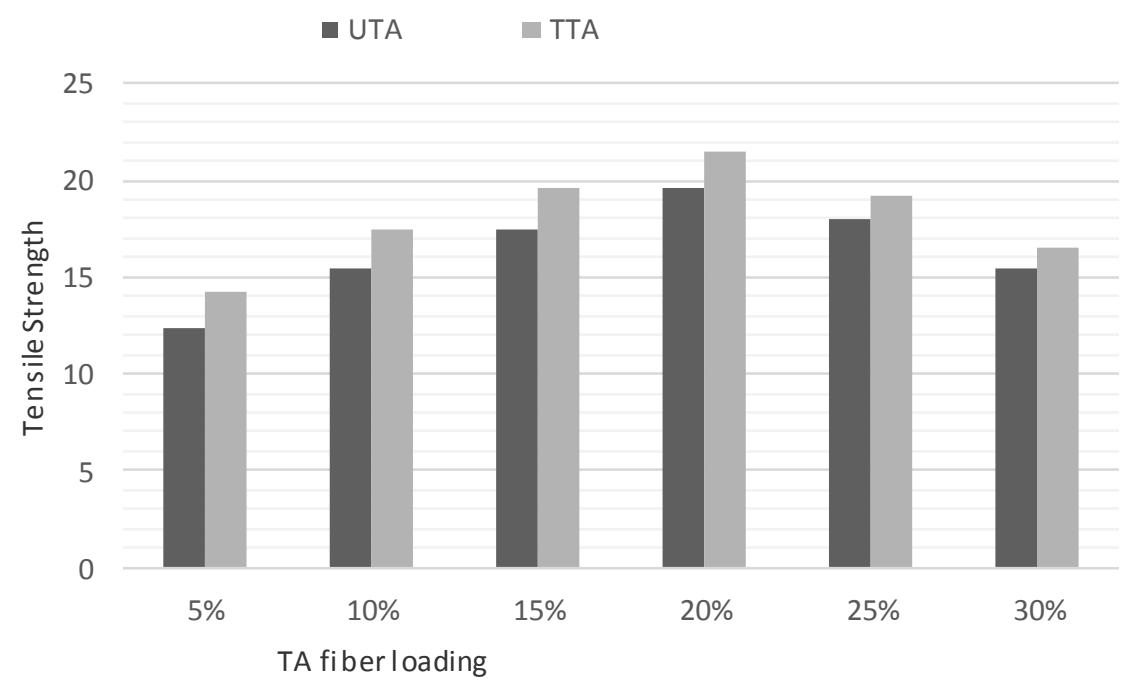

Figure 5:-Tensile strength (Mpa) vs Fiber loading (wt. \%). 


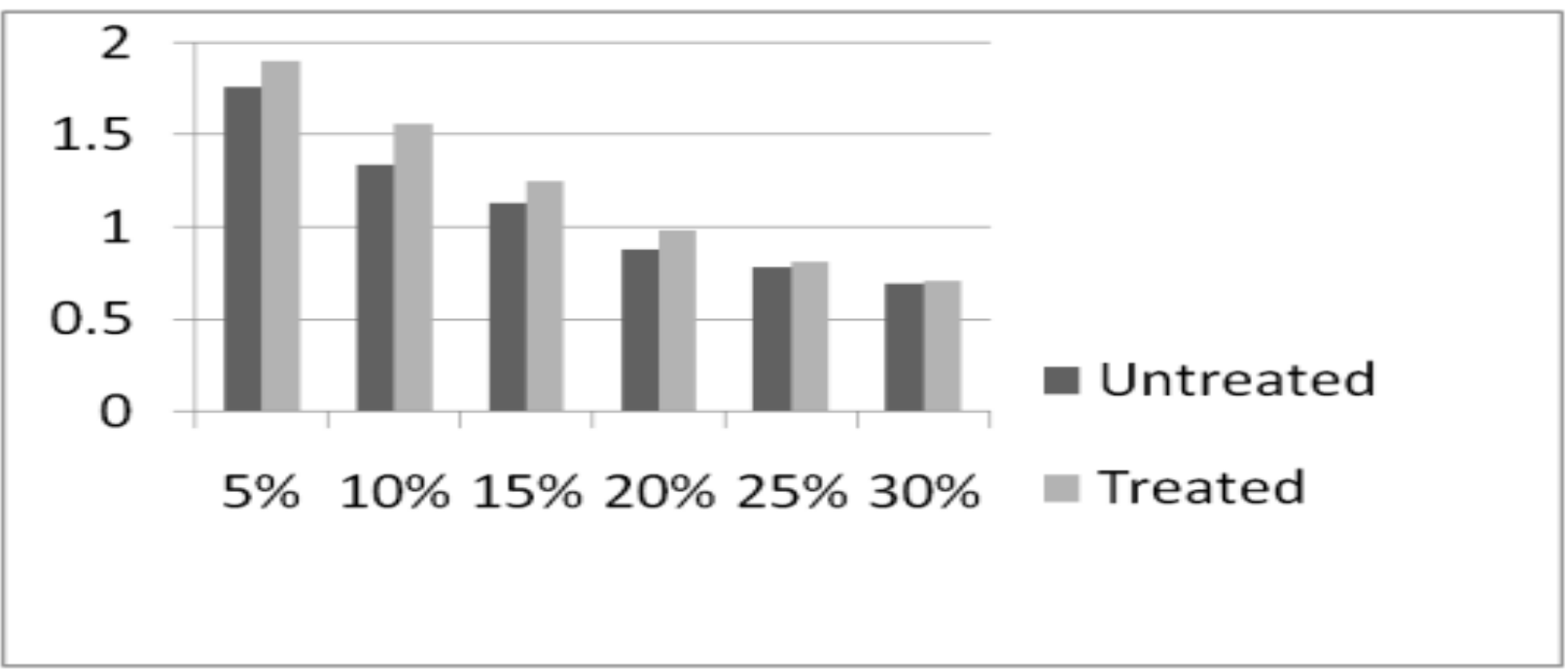

Figure 6:- Elongation at break vs fiber Loading (wt. \%)

\section{Water absorption:-}

Water absorption test results of all treated and untreated TAF- Polystyrene composites are shown in Fig.7. From the figure it is clear that water absorption of untreated TAF-Polystyrene composites is higher than that of treated TAFPolystyrene composites but water absorption is increased with increasing of fiber loading for all composites. This may be due to the hydrogen bonding formation of water molecules with the hydroxyl groups in the constituents of lignin, hemicelluloses and cellulose of untreated TAF. Hemicelluloses were completely removed and lignin was reduced by alkali treatment of TAF. So treated TAF - Polystyrene composites show less water absorption than untreated TAF- Polystyrene composites. So dimension stability will be higher for treated TAF-Polystyrene composites than untreated TAF- Polystyrene composites.

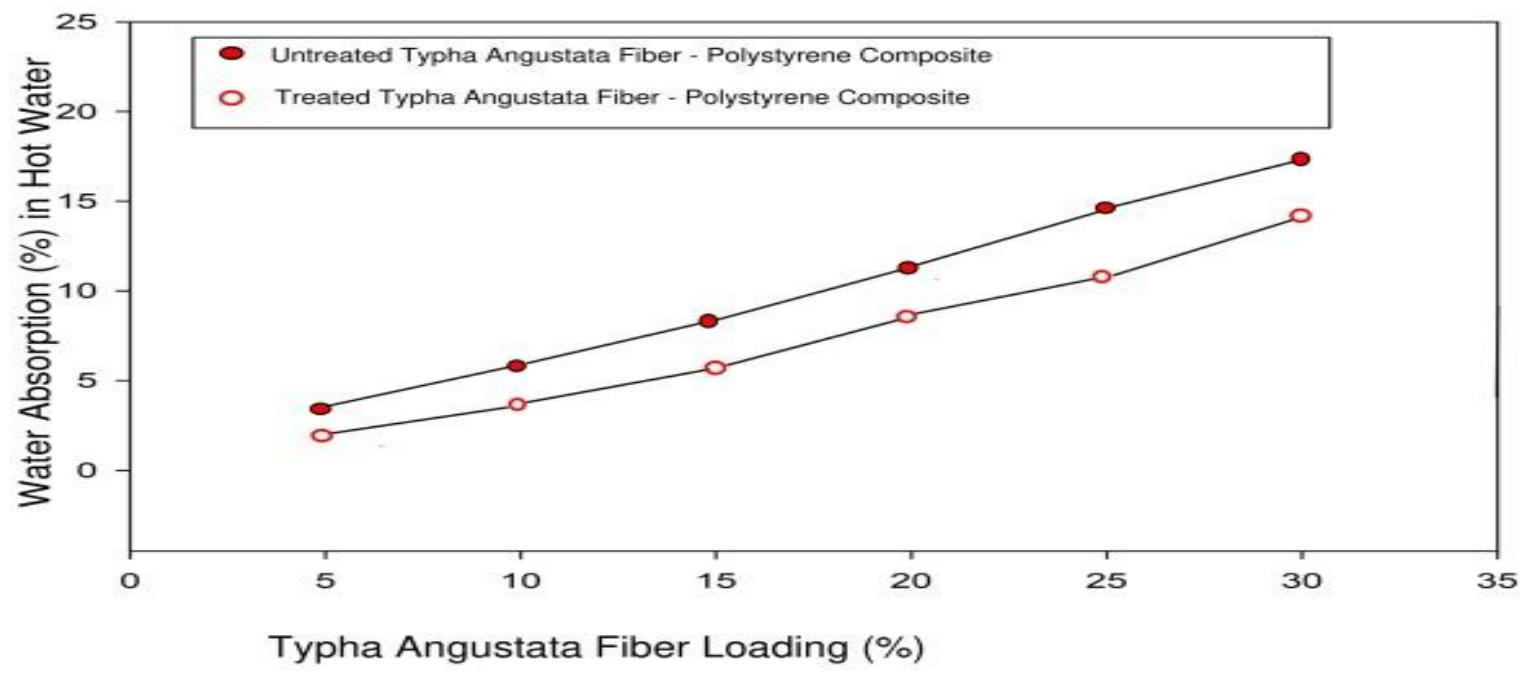

Figure 7:- Water absorption vs TA fiber loading

\section{Morphological analyses:-}

The scanning electron microscopy (SEM) images of untreated and treated typha angustata fiber-polystyrene composites are shown in figure 8 and 9 respectively. A uniform dispersion and better interfacial adhesion between the fiber and matrix is observed in figure 9 which represents the fracture surfaces of $25 \mathrm{wt} . \%$ alkali treated TAFpolystyrene composite. On the other hand the SEM Micrograph of the fracture surface of $25 \mathrm{wt}$. \% untreated TAF- 
polystyrene composites shows weak interfacial adhesion between the fiber and matrix. So it may be concluded that alkali treated TA fibers are able to improve the compatibility between the fiber and matrix in the composites

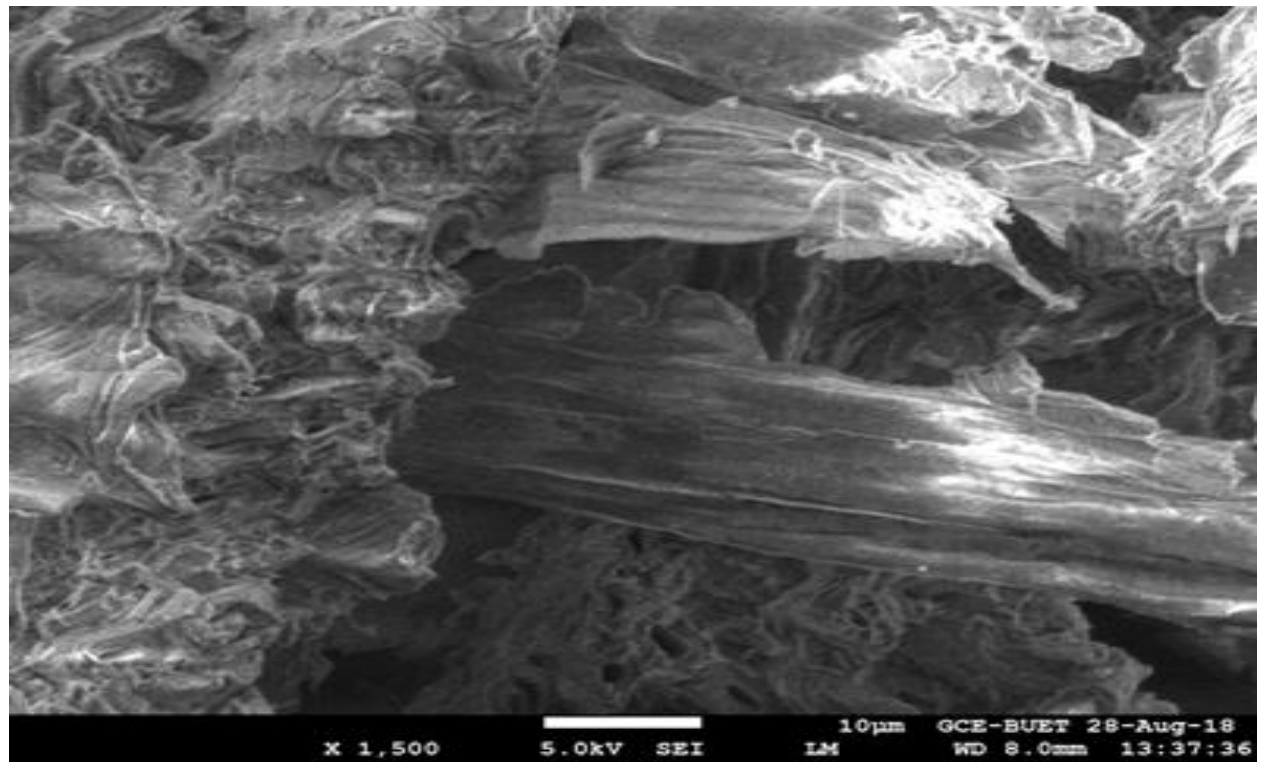

Figure 8:- SEM image of untreated 20wt. \% TAF - Polystyrene composite.

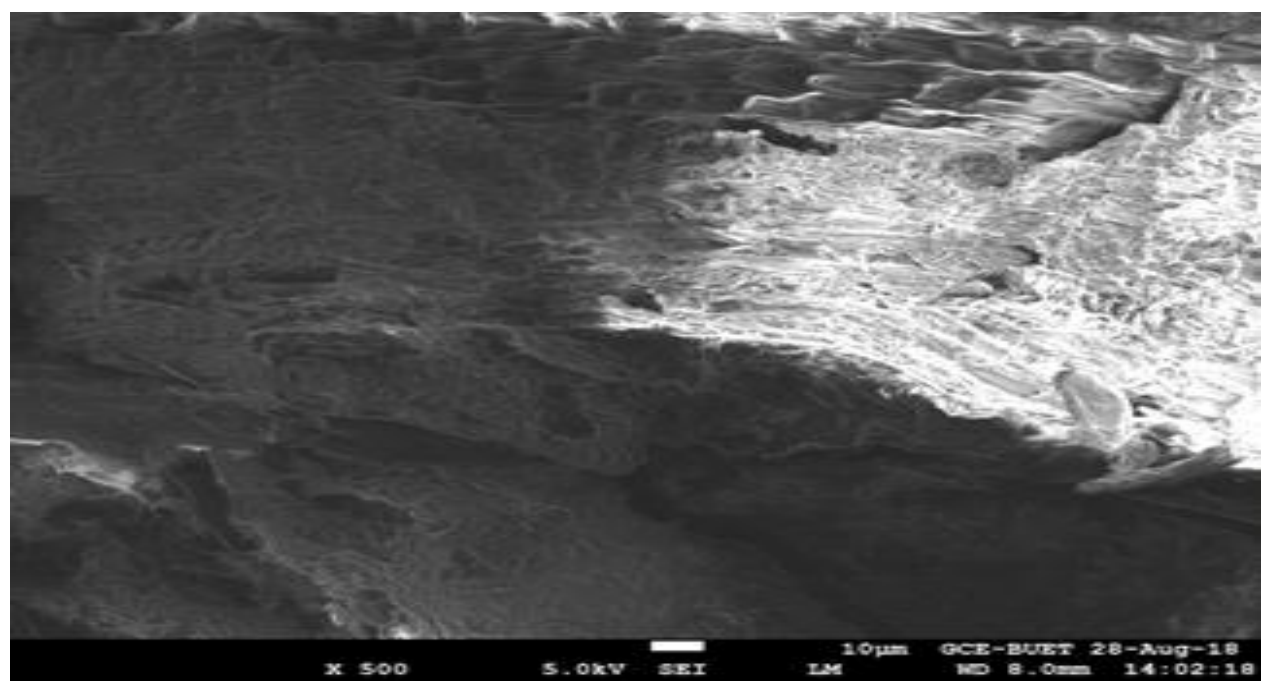

Figure 9:- SEM image of alkali treated 20wt. \% TAF - Polystyrene composites.

\section{Conclusion:-}

The alkali treatment of typha angustata fibers reduces the lignin content of fibers, the moisture absorption property and removes the impurities and hemicelluloses and FT-IR spectroscopic analyses also support the evidence of removal of hemicelluloses. Alkali treatment of TAF improves the interfacial adhesion between fibers and matrices in composites. The enhancement of the hydrophobicity in TAF due to alkali treatment gives the better compatibility between the fibers and matrices of the polystyrene composites. The tensile properties of treated TAF -Polystyrene composites are higher than that of untreated typha angustata fiber-polystyrene composites. The reduction of water absorption in the alkali treated TAF-polystyrene composites will increase their dimensional stability. The strong interfacial bonding between fibers and matrices in the alkali treated TAF-Polystyrene composites was proved by the morphological observation. It is expected that different thermoplastics based composites would be developed by using this method. 


\section{Acknowledgement:-}

This work was supported by Department of Chemistry, Bangladesh University of Engineering \& Technology. The authors express their sincere gratitude to BCSIR and Glass and Ceramics Department, BUET for additional supporting the research work. Authors are thankful to the management of Canadian University of Bangladesh for providing the facilities and support for the successful completion of the work.

\section{References:-}

1. J. Zhu., H. Zhu., J. Njuguna. \& H. Abhyankar., Materials., 6, P. 5171-5198 (2013).

2. J. W. S. Hearle., W. E. Morton., Physical Properties of Textile Fibers, ELSEVIER., $4^{\text {th }}$ edn, (2008).

3. A, Kumar. K., International Journal of Phytopharmacology, 4(4), P. 277-281 (2013).

4. P. Gaikwad., P. Mahanwar., \& V. Bambole., International Journal of Chemical, Environmental \& Biological Sciences (IJCEBS)., 2 (4), P.181-186, (2014).

5. P. Gopal., \& V. K. B. Raja., Research Journal of Pharmaceutical, Biological and Chemical Sciences., 8(2), P. 457-461 (2017).

6. A. Gupta., \& A. Kumar., Asian Journal of Chemistry., 24(4), P. 1831-1836 (2012).

7. J. P. Siregar., S. M. Sapuan., M. Z. A. Rahman. \& H. M. D. K. Zaman., Journal of Food, Agriculture \& Environment., 8 (2), P. 1103 - 1108 (2010).

8. P. Ponnukrishnan., M. ChithambaraThanu., S. Richard., Mechanical Characterization of Typha Domingensis Natural Fiber Reinforced Polyester Composites, 2328-3491, P. 241-244 (2014).

9. S. Tanvir., S. Shahin., N. P. Husna., M. W. Khan., International Journal of Advance Research (IJAR)., 6(2),P. 202-209 (2018).

10. S. Dhanalakshmi., P. Ramadevi., G. R. Raghu Patel., M. Manikanta., K. Kiran., A. Jayaraj., M. Jason., G. R. Chethan., B. Basavaraju., Effect of fiber loading and surface modification on tensile behavior of natural areca composites, Ciencia-e - Tecnica Vitivinicola, 29(8), P. 99-114 (2014).

11. S. Dhanalakshmi., B. Basavaraju., P. Ramadevi., Areca fiber reinforced polypropylene composites: Influence of Mercerization on Tensile behavior, International Journal of Material Science and Manufacturing Engineering, 41, P. 1151-1156 (2014).

12. S. Dhanalakshmi., P. Ramadevi., B. B. Basavaraju., P. R. Raghu., C. V. Srinivasa., Natural areca fiber: surface modification and spectral studies, International Journal of Advance Chemistry, 10(10), P. 3263-3273 ( 2014 ).

13. S. V. Prasad., C. Pavithran., P. K. Rohtgi., Alkali treatment of coir fibers for coir-polyester composites, International journal of material science, 18(5), P. 1443-1454 (1983).

14. L. Xue., G. T. Lope., P. Satyanarayan., Chemical treatment of natural fiber for use in natural fiber-reinforced composites, journal of polymers and the environment, 15(1), P. 25-33 (2007).

15. Y. M. Leonard., T. Nick., J. C. Andrew., Mechanical properties of hemp fiber reinforced euphorbia composites, Macromolecular Material and Engineering, 292(9), P. 993-1000 (2007).

16. R. Dipa., B. K. Sarkar., A. K. Rana., N. R. Bose., Effect of alkali treated jute fibers on composite properties, Bulletin of Material Science, 24(2), P. 129-135 (2001).

17. M. M. Rahaman., A. K. Mallik., M. A. Khan., Influences of various surface treatments on the mechanical and degradable properties of photo grafted palm fibers, Journal of Applied Polymer Science, 10(5), P. 3077-3086 (2007).

18. N. K. C. Manikandan., S. Thomas., G. Groeninckx., Thermal and dynamic mechanical analysis of polystyrene composites reinforced with short sisal fibers, Composite Science and Technology, 61(16), P. 2519-2529 (2001).

19. M. M. Kabir., H. Wang., K. T. Lau., Chemical treatments on plant-based natural fiber reinforced polymer composites: An overview, Composites Part B, 43, P. 2883-2892 (2012).

20. P. V. Joseph., Studies on short Sisal Fiber Reinforced Isotactic Polypropylene Composites, PhD Thesis. School of Chemical Sciences, Mahatma Gandhi University, Kottayam, Kerala, India, May 2001.

21. K. C. Manikandan Nair., Short Sisal Fiber Reinforced Polystyrene Composites, PhD Thesis. School of Chemical Sciences, Mahatma Gandhi University, Kottayam, Kerala, India, 2002. 